\title{
THE Rules OF LiABILITY AND THE ECONOMICS OF CARE
}

\author{
Conrad Blyth ${ }^{*}$ and Basil Sharp**
}

\section{Introduction}

The New Zealand Law Commission has proposed changes to the rules of liability applied in cases of negligence under the law of torts. ${ }^{1}$ However, the Commission proposes to retain the rule that where there are two wrongdoers who together cause a single loss each is liable to the injured person for up to $100 \%$ of the plaintiff's claim. Is this rule justified economically? This paper proposes to analyse the rule (called here the doctrine of "solidary liability") in economic terms. Looking at the solidary liability rule and its alternatives, which one affords potential wrongdoers the best incentive to take appropriate levels of care?

The doctrine of solidary liability allows a plaintiff to recover the full amount of an award of the damages arising from a tortious act or omission from any one or any combination of the defendant tortfeasors who contributed to the injury, as long as the total claim is limited to the full amount of the damages. Thus any one defendant may be liable to pay $100 \%$ of the plaintiff's loss.

The main alternative rule, which is called here "proportionate liability", limits the plaintiff's claim to the proportion of damages allocated by the court to each defendant. Thus any one defendant is liable only for his or her own proportion of the plaintiff's damages. Given that the courts have to determine damages under both rules, the significant difference between solidary and proportionate liability lies in the costs of apportioning damages commensurate with fault and the possibility of missing defendants.

Under the solidary rule there is the possibility that in the event of a claim for damages, the defendant or defendants may claim a contribution to (share of) the damages from other joint wrongdoers. The standard procedure in New Zealand links the two claims: the plaintiff sues defendant 1 who issues proceedings joining defendant 2 as a third party

* Emeritus Professor, Department of Economics, University of Auckland.

** Associate Professor, Department of Economics, University of Auckland.

1 Law Commission Apportionment of Civil Liability (Preliminary Paper No 19, Wellington, 1992). 
before the plaintiff's claim is heard. This possibility obviously allows an element of proportionality to enter into the solidary rule. Consequently two solidary rules are distinguished: with and without a claim to contribution.

Briefly, the Law Commission's proposals are these. The plaintiff's contributory fault should first be assessed as a proportion against all the defendants together. The solidary liability rule should remain unchanged. There should, however, be a right of contribution amongst defendants, whatever the basis of civil liability. The plaintiff and solvent defendants should then proportionately share between them the burden caused by missing, insolvent or judgment proof defendants. While elements of proportionate liability thus enter these proposals, the Commission has not endorsed suggestions that solidary liability be replaced by proportionate liability.

In contrast, in Australia the Davis Inquiry more recently recommended that the present solidary liability of defendants in actions for negligence causing property damage or pure economic loss be replaced by "liability which is proportionate to each defendant's degree of fault." 2

The existing rules of liability have been coming under criticism outside the legal profession, particularly from accountants. The background to the Australian inquiry was the concerns of, amongst others, international accounting firms that they are becoming the sole target for legal actions (ie the deep pocket) to the point where insurance is becoming unobtainable. ${ }^{3}$ Territorial local authorities are exposed in a similar way to actions brought by owners of buildings.

It is obviously of considerable interest to know what are the economic consequences arising from the adoption of alternative rules of liability. The present authors have recently completed a report for the Law Commission entitled Solidary and Proportionate Liability: An Economic Analysis the main conclusion of which is that proportionate liability provides the closest approach to an optimum allocation of economic resources, although solidary liability with contribution would closely approximate it in certain circumstances. In this article we attempt to provide a relatively non-technical economic analysis of the rules of

2 J L R Davis Inquiry into the Law of Joint and Several Liability (Report of Stage Two, Commonwealth of Australia, 1995), 2. In the interest of a concise style we use the term "solidary" instead of "joint and several" as used by the Law Commission and by the Australian Inquiry, and in preference to "in solidum". The term "proportionate" for the alternative liability rule we have borrowed from the Australian Inquiry instead of "several" which appears in the Commission's paper.

3 See R Mednick and J J Peck "Proportionality: a much-needed solution to the accountants' legal liability crisis" (1994) 15 Valparaiso University L Rev, 867; P Bargren "Joint and several liability: protection for plaintiffs" [1994] Wisconsin L Rev 453; and J Granelli "The attack on joint and several liability" (1985) 71 ABA Journal The Lawyer's Magazine (July issue) 61-63. 
liability and to explain our conclusions. In so doing we may clarify both the benefits and the difficulties of an economic approach.

Our approach is to start with the conditions which produce an optimal allocation of economic resources in society. This optimal allocation is one which minimises total social cost. Hence one liability rule is relatively more economically efficient than others if it provides better incentives for potential tortfeasors to take levels of care that minimise total social cost: this cost being the sum of both precaution and loss (damage) costs. The allocation of economic resources at any time depends upon particular circumstances. The particular circumstances relevant here are a given degree of knowledge (eg of producing economic goods), a given degree of uncertainty about the future, a given degree of competition in markets and a given legal system. Economic agents (households, firms) faced with these particular circumstances have incentives to take decisions which result in a particular allocation of resources. We are specially concerned with the incentives provided by the expectation that in the event of a commercial dispute (eg over the building of a house or the auditing of a firm's financial records) the court will apply a particular liability rule. These incentives may or may not result in an optimal allocation of resources.

\section{The Market in Care}

Buyers and sellers in markets agree on (contract about) matters besides price, quantity and date of payment: let us call the other matters quality as a generic term. Bad quality ranges from rotten lemons to a house whose foundations collapse to an audit which fails to disclose an impending insolvency. In order to avoid bad quality, and produce acceptable good quality, it is necessary to exercise care (or precaution). Care is an economic good: its production absorbs scarce economic resources and its opportunity cost is the other goods that are unable to be produced because of the allocation of resources to the production of an amount of care. It follows that care has a price, and we can imagine a market in care in which some economic agents demand care while others supply care (some who demand care may be capable of supplying it themselves). For each agent, the amount of care supplied and demanded at a particular price will not necessarily be uniform: that will depend upon the particular agent's preferences and opportunity costs - as is the case in any market.

To apply market analysis to care we must make some important assumptions. The first is that a unit of care is defined unambiguously: we may suppose that it is defined in terms of inputs (eg time spent in taking care) or outputs (eg quality of finished product). All who trade in quantities of care know that any one unit is substitutable for any other (although their costs of production may differ). Secondly, we assume that trading in care takes place by means of standard contracts for so many standard units at the agreed price. In the care market (which we suppose for simplicity is competitive) the price of a unit of care is determined by total supply and demand; each supplier then produces care up to the point where the marginal cost of that supplier equals the price. Diagram 1 illustrates the situation 
in an auditing example which contains three agents: owner, manager and auditor. In panel (a) the curve DD represents the demand schedule of the owner for care: the higher the price the less care demanded. Price is measured on the vertical axis; quantity of care on the horizontal. In panels (b), (c) and (d) the supply of care by the owner himself, the manager and the auditor respectively are represented by curves mc which represent the supply (marginal cost) schedules of the suppliers. In panel (a) these three supply schedules are summed horizontally to provide a market supply curve SS. The point of intersection of the DD and SS curves defines the market equilibrium where a price $\mathrm{p}^{*}$ is set which makes quantity supplied equal to quantity demanded, $c^{*}$. At this price $p^{*}$ we can read off on the other panels the quantity of care supplied by each of the three agents, $w^{*}, x^{*}$ and $y^{*}$, the sum of which equals $\mathrm{c}^{*}$.

\section{Diagram 1: Market for care}

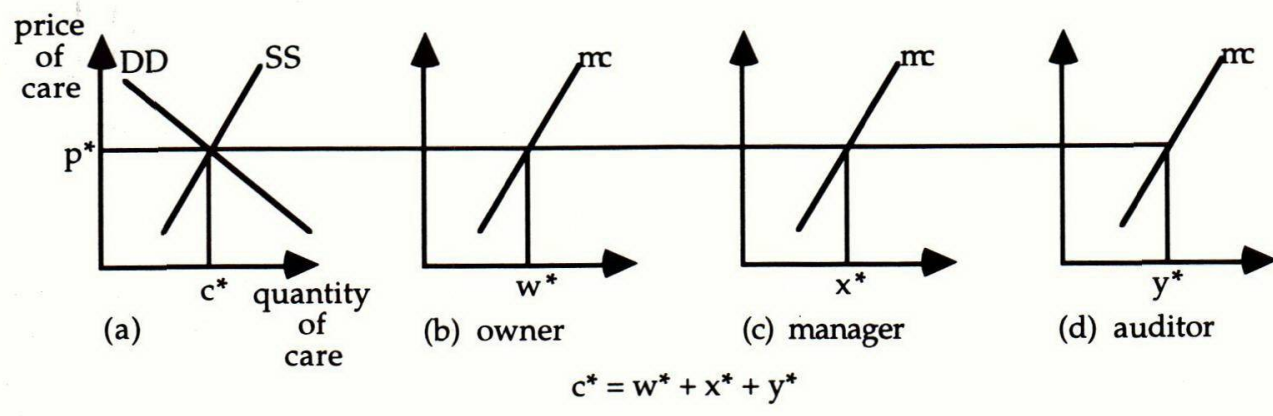

The above is a traditional analysis of a market. If furthermore we explicitly assume competitive conditions, we may conclude that the allocation of economic resources to care is optimal in the circumstances described: no supplier of care will be able to earn more than normal profits in the long run. ${ }^{4}$

The analysis is usually interpreted in a setting of contract law as described here. What happens if the owner experiences an unexpected loss of profits of the amount D? The purchase of the amounts of care $x^{*}$ and $y^{*}$, and supply of $w^{*}$, by the owner represent acceptable risks of loss, and we might suppose that over time these amounts and risks become customary in the market place. Thus if the owner does in fact suffer loss $D$, and it is shown that the amounts of care supplied by the others were in fact less than the contracted or customary amounts, say $x^{\prime}$ and $y^{\prime}$, we might expect the auditor and the manager to share the loss in proportion to the amounts of contracted or customary care which were not supplied, $x^{*}-x^{\prime}$ and $y^{*}-y^{\prime}$. If as well the owner had failed to supply $w^{*}$, that is the amount of care which the market customarily expected of an owner, the owner might be expected to

4 The analysis can also be extended to imperfectly competitive markets (monopoly or oligopoly). 
share the loss in the appropriate proportion: see Diagram 2, where the shares of the loss are calculated as:

$$
\begin{array}{ll}
\text { owner } & \left(w^{*}-w^{\prime}\right) /\left(c^{*}-c^{\prime}\right) \\
\text { manager } & \left(x^{*}-x^{\prime}\right) /\left(c^{*}-c^{\prime}\right) \\
\text { auditor } & \left(y^{*}-y^{\prime}\right) /\left(c^{*}-c^{\prime}\right)
\end{array}
$$

Diagram 2: Market for care with unfulfilled contracts

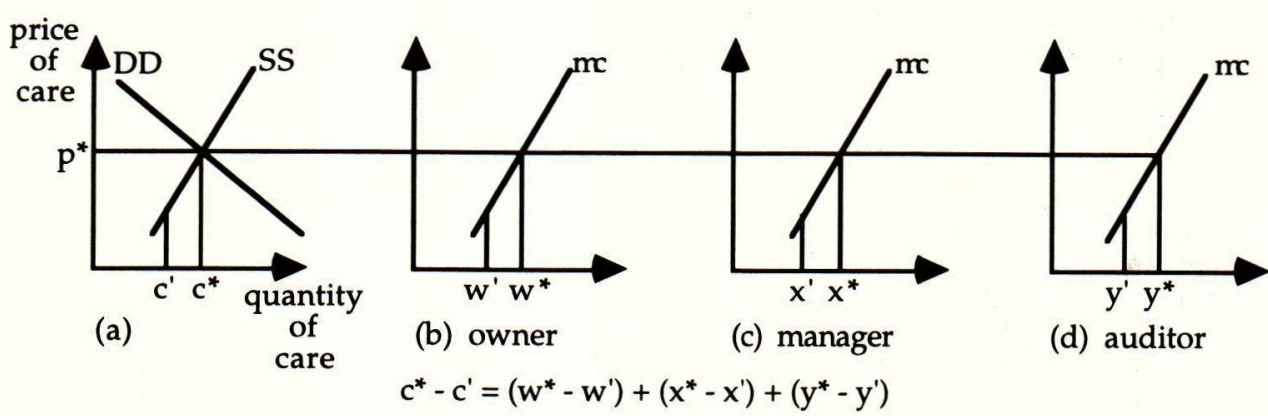

The significance of the above analysis lies in the incentives provided to the three agents (who are aware of these consequences of not fulfilling contracts and of the use of a proportionate rule for allocating loss) to supply care up to the contracted or customary level. This of course means that the agents have incentives to take decisions which will result in an efficient economy. The market model provides a useful starting or reference point in the analysis. It is however removed from some of the realities we must be concerned with.

The inclusion of quality (along with quantity and price) as a dimension in the above economic analysis has not moved away from the traditional (neo-classical) model of market behaviour. Furthermore, in order to deal with quality by means of the concept of care it has been necessary to assume simple transactions involving the buying and selling of a standardised commodity "care". These transactions are governed by contracts. In the case of a contract to build a house the document might be very detailed, to the point of specifying types of materials and methods of construction, together with required standards of operation or performance before final payments are made. Such detailed contracts and their monitoring are costly. Furthermore, disagreement in their interpretation is possible, and arbitration or recourse to the courts is also costly. ${ }^{5}$ Consequently, the potential plaintiff

5 Strictly speaking, the market model assumes that transaction costs are zero: such costs include both the writing and the monitoring of the performance of contract. 
may prefer a simple contract, relying on a remedy in either contract or tort in the event of a loss through negligence. In the present discussion it is assumed that the parties involved in the transaction, aware of the possibility of eventual disagreement over the level of care, choose a particular type of contract to suit their circumstances and also to suit their assessment of the risks surrounding the transaction. This choice has certain well understood implications regarding negligence and liability for damages under the law of torts. ${ }^{6}$ The point being made here is that the transaction between the economic agents must embrace, along with its narrowly "economic" aspects such as price, quantity, quality, delivery date etc, a full joint understanding of the economic consequences - expected costs, risks, etc - of liability for possible losses if the decisions taken are to result in an optimum allocation of resources. This full joint understanding includes the legal setting and expected legal consequences within which the transaction takes place. ${ }^{7}$

We now turn to an alternative analysis of the demand and supply of care which is suitable for a legal framework of negligence and concurrent liability.

\section{Care and Negligence}

Suppose a manager can act so that the owner of a firm is likely to lose money and the auditor can fail to discover the acts of the manager. ${ }^{8}$ In the simplest case where the auditor is the sole tortfeasor providing care $y$, let the loss (damage) suffered by the owner be $D$. As in the market model, the cost of care, $\mathrm{B}(\mathrm{y})$, increases as the quantity of care supplied increases. However there is another cost factor for the auditor to consider: the expected loss to the owner: the more care that is provided by the auditor the lower the probability of the loss occurring. If $\operatorname{prob}(y)$ is the probability of loss, the expected loss is prob(y)D. Thus the auditor faces expected costs

$$
\mathrm{L}(\mathrm{y})=\mathrm{B}(\mathrm{y})+\operatorname{prob}(\mathrm{y}) \mathrm{D}
$$

The choice facing the auditor is illustrated in Diagram 3. $y^{*}$ is the level of care which minimises costs: this represents the optimum allocation of economic resources in the long

6 It appears to be generally held that "...tort law supplements contract law by devising rules for apportioning losses in situations where it is too costly for potential injurers and potential victims to enter into a contractual relationship to make that apportionment". R Cooter and T Ulen Law and Economics (Harper Collins, USA, 1988), 341.

7 As an aside, it would appear that insofar as an optimal economic allocation of resources presupposes (amongst other matters) a perfectly competitive market in legal advice, the optimal allocation also presupposes the choice of the optimum legal framework (wherever such a choice is possible) for each transaction. Thus a contract would be tailored to the circumstances, taking into account the transaction costs which might leave much to be dealt with by the law of torts as suggested in the preceding footnote.

8 See the references cited above $\mathrm{n} 3$. 
run. ${ }^{9}$ If the legal standard of care defined by the courts is also $y^{*}$ it is obviously in the auditor's interest to select $y^{*}$. However the quantity of damages determined by the courts will also have an effect on the auditor's choice: if the courts are expected to award D1>D the cost mimimising level of care is $y^{* *}$. If on the other hand the courts set $y+$ as the required legal standard, there is no incentive for the auditor to take precautions beyond $y+$. It will be understood that the desirable effect of incentives depends upon those incentives being understood by all parties. This in turn depends very much in practice on the courts adopting consistent standards for required care and acting consistently in the award of damages.

\section{Diagram 3: Simple negligence}

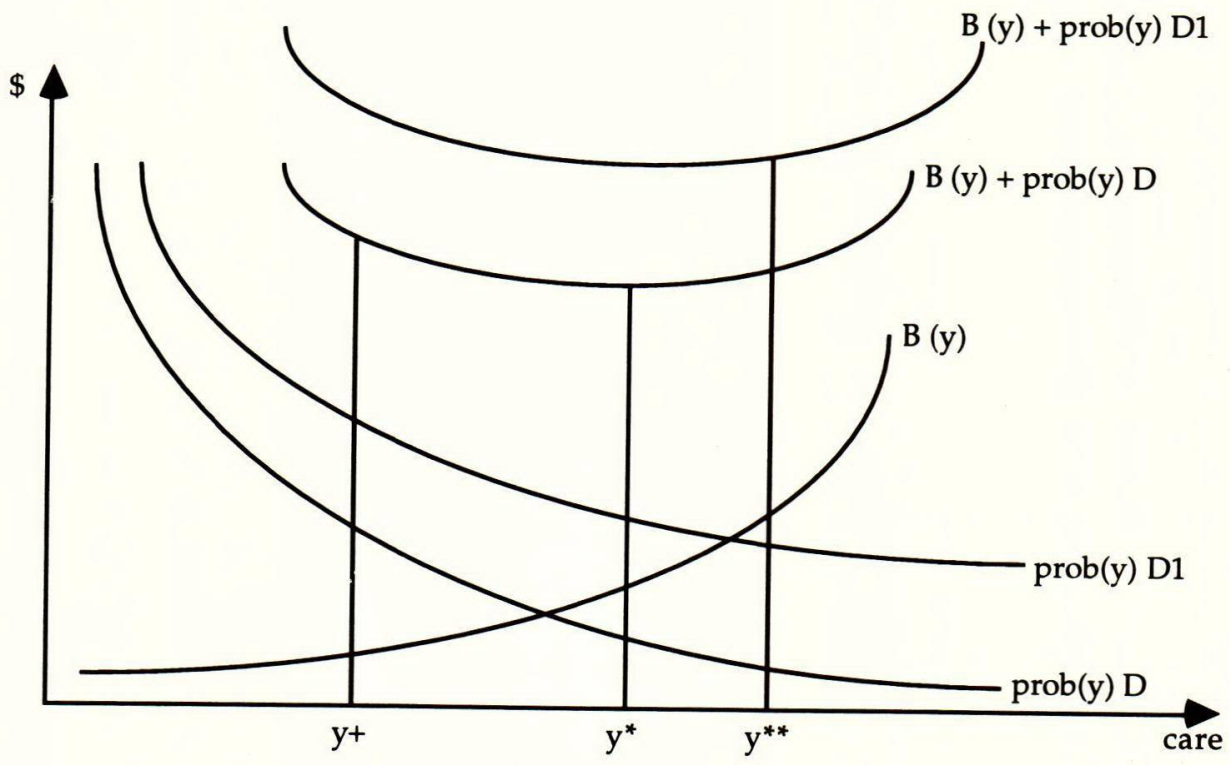

\section{Joint Responsibility for Care}

The simple model of negligence can be extended to more than a single tortfeasor and can include the contributory negligence of a plaintiff. ${ }^{10}$ We illustrate for the case of two tortfeasors and an owner plaintiff whose costs are written as follows:

9 The relationship between the minimum total cost in Diagram 3 and the optimum allocation of resources illustrated in Diagram 1 lies in the fact that the rising marginal cost to the auditor of producing care (the first derivative of $B(y)$ ) at the point of minimum total expected cost equals the declining marginal expected loss (the first derivative of $\operatorname{prob}(y) D$ ).

10 W M Landes and R A Posner "Joint and multiple tortfeasors: an economic analysis" (1980) 9 The Journal of Legal Studies 517. See also W M Landes and R A Posner The Economic Structure of Tort Law (Harvard University Press, Cambridge, 1987). 
$\mathrm{A}(\mathrm{w})=$ the cost to the owner of exercising care $\mathrm{w}$

$\mathrm{B}(\mathrm{x})=$ the cost to the manager of exercising care $\mathrm{x}$

$C(y)=$ the cost to the auditor of exercising care $y$

The probability of loss depends upon the level of care exercised by each party, and can be written as prob $(w, x, y)$. As before, the total expected costs which we use as the criterion for optimum allocation is the sum of expected loss and care costs:

$$
L(w, x, y)=\operatorname{prob}(w, x, y) D+A(w)+B(x)+C(y)
$$

and the optimum level of care $\left(w^{*}, x^{*}, y^{*}\right)$ minimises expected costs L. Note that the choice of any one party is influenced by the behaviour of all parties: the probability of loss is contingent on the behaviour of all parties. ${ }^{11}$

Would the parties (who we assume are rational economic people) choose the least cost levels of care? The answer is - not unless the rule of liability provides each of them with the appropriate incentive. Suppose the parties in our example considered choosing levels of care $\left(w^{\prime}, x^{\prime}, y^{\prime}\right)$ less than the minimum cost levels. At the same time suppose they were aware that the respective liabilities for the loss would certainly be assessed by the court in proportion to the shortfall between the actual and the least cost levels of care, ie in proportion to $w^{*}-w^{\prime}, x^{*}-x^{\prime}$ and $y^{*}-y^{\prime}$ (as in the market model analysed above). In these circumstances each party has an incentive to choose the optimum (least cost) level of care. Thus we conclude that proportionate liability would provide an incentive for economic actors to behave in an economically efficient way. ${ }^{12}$

This conclusion may not always hold; there may be disturbing circumstances eg:

- care may not produce determinate results (there may be uncertainty as to the amount of care required to achieve a particular result)

- each party may have different assessments of the probability of damage (although over time consistent expectations will arise in industry)

- courts may make errors in applying the standard in particular cases (although the requirement is that over time the courts' decisions will approach the least cost levels of care).

11 In the above equation, $\mathrm{D}$ is a constant.

12 The situation described here is a so-called Nash equilibrium which relies on a coordinating mechanism which gives agents a mutually consistent set of expectations necessary to achieve the choice of cost-minimising levels of care. In the example the coordinating mechanism is provided by the courts delivering clear and consistent messages in awarding damages so as to provide the appropriate incentives. See H Moulin Game Theory for the Social Sciences (New York University Press, New York, 1986). 


\section{$V$ The Liability Rules: Relative Economic Efficiency}

In this section we summarise our conclusions about the economic efficiency of the two basic liability rules, proportionate and solidary, distinguishing in the case of solidary the sub-categories of with and without contribution. Initially we assume that all shares of damages are collectable (no missing or unreachable defendants); we also initially assume that transaction costs, including adjudication and other legal costs, are zero.

\section{A The standard case: proportionate liability}

In the standard case all shares are believed by the parties to be collectable and the cost and expected loss functions are known. Under proportionate liability the courts would determine the damages $\mathrm{D}$, whether each tortfeasor's care reached the optimum standard $\left(w^{*}, x^{*}, y^{*}\right)$ and the share of damages borne by each tortfeasor. Proportionate liability, provided the courts correctly assess the damages and apportion the shares, should provide sufficient incentive for an efficient outcome.

\section{B Solidary liability without contribution}

Under this rule, if a plaintiff elects to sue a defendant and the court finds the latter bearing partial responsibility for the loss, the plaintiff can recover the entire loss from the defendant who has no right to reimbursement (contribution) from other defendants. The share of damages which any potential defendant might anticipate bearing should the care level be below the standard may vary uncertainly from zero to $100 \%$ (compared with a known proportion in the standard case). The probability of being listed as sole defendent will differ for different potential tortfeasors. The uncertainty of legal outcome surrounding this case is in marked contrast with the degree of certainty of the proportionate liability case. This uncertainty itself makes it unlikely that the parties will choose the minimum cost levels of care: simply, they have no incentive to do so. The special case of deep pocket is considered below.

The potential defendants in estimating their chances of being sued may indeed estimate these chances at precisely the same proportions as the contributions they would expect to make under a contributory system, but this result is in no way inevitable: if it did occur it would depend on particular circumstances.

The essential economic difference between proportionate and solidary liability is illustrated in Diagram 4 which reproduces Diagram 3 but is interpreted differently. 


\section{Diagram 4: Proportionate and solidary liability}

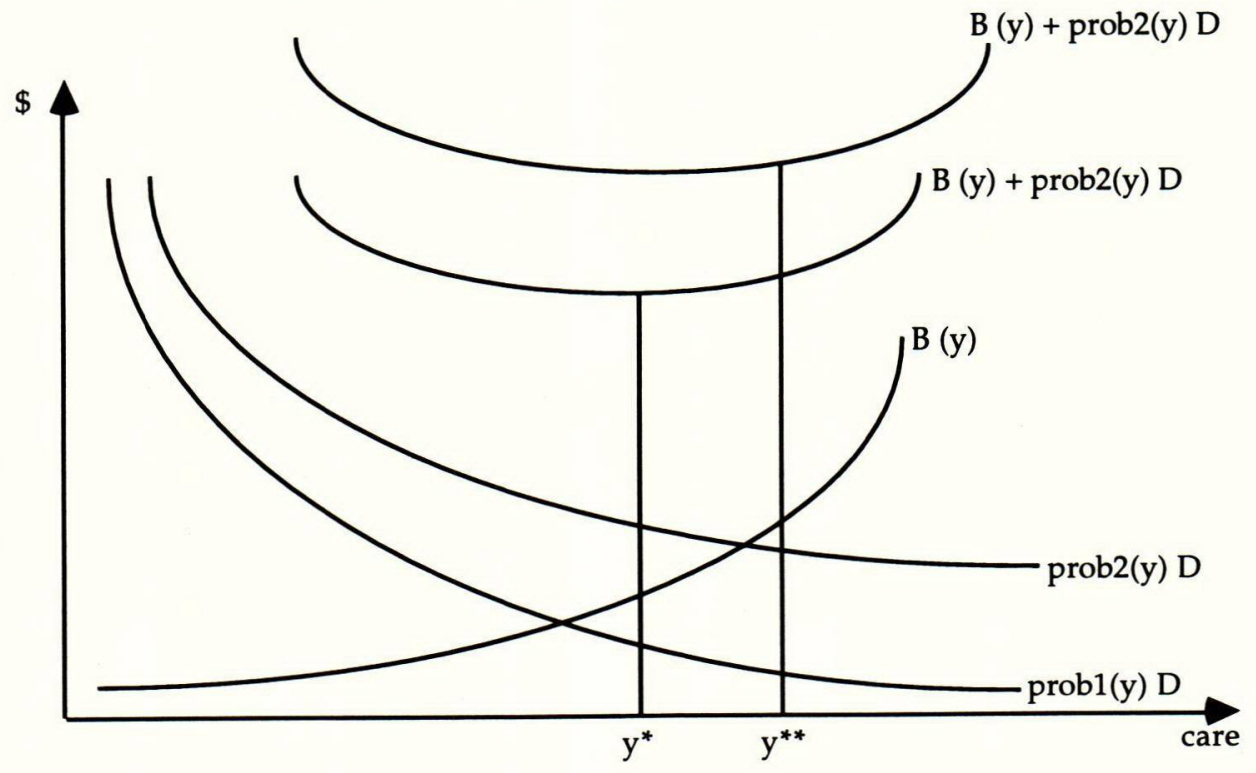

We start with the proportionate case and assume that for one of the parties, say the auditor, prob1(y) describes the probability of loss (damage) declining as care increases, and prob1(y)D the expected loss in dollars. With the cost of care $B(y)$, total expected costs are

$$
\mathrm{B}(\mathrm{y})+\operatorname{prob1}(\mathrm{y}) \mathrm{D}
$$

and the auditor has the incentive to choose the level of care, $\mathrm{y}^{*}$, which minimises total expected costs. All of this is as above in Diagram 3. Contrast this result with a solidary rule without contribution (imagine one rule is substituted for the other). For all the potential tortfeasors, including the auditor, the uncertainty as to which one might be sued increases the expected loss in dollars at each possible level of care. We interpret this as an increase in the probability of loss at each possible level of care. This is shown in the diagram as the new curve prob2(y)D (representing the solidary rule) drawn higher than the old curve prob1(y)D (representing the proportionate rule). In consequence, when we calculate the total expected costs by summing the cost of care and the new, higher expected loss ie:

$$
\mathrm{B}(\mathrm{y})+\operatorname{prob2}(\mathrm{y}) \mathrm{D}
$$

we find that the new total expected cost curve is higher than is the old curve, and the level of care required to minimise total expected costs, $y^{* *}$, is greater than the old level of care, $\mathrm{y}^{*}$. Thus we conclude that in general the effect of the application of the solidary rule on economic incentives is to increase levels of care by all potential tortfeasors (but not 
necessarily by the plaintiff). Thus compared with the proportionate rule the solidary rule is sub-optimal or in simple terms economically wasteful.

\section{Solidary liability with contribution}

In the initial comparison with the no - contribution case, we are as before assuming that transaction costs, which include the adjudication and other legal costs, are zero.The expected costs for each potential injurer are the same as for proportionate liability, and there is no uncertainty about the tortfeasor sued by the plaintiff being able to take action against the remaining tortfeasors.

The economic differences between the rules we are analysing can be seen by using again Diagram 4. Imagine that having shifted from using a proportionate rule with optimum level of care $y^{*}$ to a solidary rule without contribution producing a higher level of care $y^{* *}>y^{*}$, we now shift to a solidary rule with contribution. For each party the risk of being faced with $100 \%$ of the loss declines, and we can imagine curve prob2(y)D which represents the expected loss shifting down towards the proportionate rule curve prob1(y)D. In the limiting situation where the uncertainty of being faced with $100 \%$ of the loss disappears, prob2(y)D coincides with the prob1(y)D and the effect of solidary liability with contribution on economic incentives is identical to that of proportionate liability.

Transaction (adjudication and other legal) costs of solidary liability with contribution are likely to be higher than for proportionate liability. Furthermore, the rule and procedures it involves also allows the plaintiff to "free ride". For instance, suppose that a manager is primarily responsible for a loss but that it would be very expensive for an owner (investor) to prove this. The owner sues the auditor who brings in the manager as a third party and, in doing so, must undertake the expense of proving the manager negligent. Insofar as all parties anticipate this situation occurring, the incentives to take care are undoubtedly affected and the optimal economic allocation is not obtained. However it would appear that this free riding situation is a consequence of the legal procedures rather than of the liability rule itself.

We thus conclude that solidary liability with contribution can approximate proportionate liability, but as the effects of free riding and the higher legal costs increase, so does the divergence from the efficiency achieved under proportionate liability. From anecdotal evidence there is good reason to believe that, because of these effects, in reality the economic efficiency of solidary liability with contribution would be less than that of proportionate liability.

\section{Uncollectible shares}

It has been explicitly assumed above that negligent defendants have not disappeared or become insolvent. The significance of the impact of the possibility of an absent co-defendant 
on the incentive structure depends upon the subsidiary rule used to allocate the absent tortfeasor's share of the damages. There are the following possibilities:

1 Proportionate liability:

either the plaintiff bears the risk (defendants pay only their respective shares of the damages);

or the remaining defendants pay their respective shares plus a portion of the share attributable to the missing tortfeasor.

2 Solidary liability (no contribution):

the risk of the missing defendant is carried by the remaining defendants and the plaintiff is fully compensated.

3 Solidary liability (with contribution):

the risk will be shared by all solvent tortfeasors.

Under the existing law each defendant is liable to meet the entire amount (less the amount due to the plaintiff's contributory negligence). The Commission's proposal is to divide the uncollectible share amongst plaintiff and remaining defendants in accordance with their degrees of negligence ie it proposes what we call solidary liability with contribution.

The probability of insolvency obviously varies between types of economic agents. An international accounting firm and a territorial local authority will have lower levels of probability than a single person building firm. In general we expect that the possibility that someone else's share will be uncollectible will strengthen the incentive of a potential tortfeasor to supply care at the minimum cost level (and thus avoid being held negligent). Proportionate liability, with the remaining defendants bearing the risk, is similar in terms of efficiency to solidary liability with contribution. Thus the possibility of uncollectible shares (anticipated in advance) reinforces the structure of incentives provided by the various rules and leaves their relative efficiency unaffected.

\section{Insurance}

When the "law of large numbers" is applicable to the events we are considering, it is possible for the risk of loss to be insurable. As before, suppose the expected damages attributable to the auditor are prob(y)D where $\mathrm{D}$ is the total possible loss (or damages) and $\operatorname{prob}(y)$ is the probability of that loss occurring, the size of the probability depending on $y$ the level of care. Let $y^{*}$ be the standard of care normally required in the profession and used by the courts as their standard. Then $\operatorname{prob}\left(y^{*}\right)$ will be the probability of loss on which insurers base their calculations of profit. Assuming the insurance industry is competitive, 
and neglecting transaction costs, the insurance premium for a normally careful auditor will be $\operatorname{prob}\left(y^{*}\right) D$. Thus the economically efficient level of care $\left(w^{*}, x^{*}, y^{*}\right)$ plays the same part in the insurance undertaken by the parties as it does in the legal disputes between the parties.

In reality, other factors intrude into the practice of insurance. The qualifications noted above ( $p$ 96) regarding the efficiency of proportionate liability apply also to insurance, in particular the random nature of the decisions of courts about the size of awards of damages. But more important for the application of the economic efficiency criterion is the fact that insurance is not always available to meet all contingencies. The balancing of events against non-events can not always be done with the certainty necessary to run a normally profitable insurance business, and markets in a wide variety of risks or contingencies do not exist: a case of so-called "market failure". ${ }^{13}$ The significance of this is that where insurance is available the risk of loss to the agent is normally reduced (to the level of the premium); but where insurance is unavailable, ie where risks can not be shared, individual actors will provide a higher level of individual care.

In some industrial and professional associations a form of insurance is provided by guarantees of compensation against loss to clients. The members of the associations can carry their own insurance or finance it through a levy on members. The effect on care provision is similar to commercial insurance. The introduction of compulsory compensation schemes, eg for owners of new homes, similar to New Zealand's accident compensation scheme, would probably result in reduced levels of individual care as the individual risk of loss was reduced; although the precise effects would depend upon the method of financing. ${ }^{14}$

\section{Deep Pocket}

A plaintiff will be disposed to sue a defendant who is known to be adequately insured or, in the case of a defendant who carries his own insurance, who is known to have adequate financial resources. We assume plaintiffs (and their advisors) act rationally and the choice of defendant is made with a view of maximising the net expected profit of suing.

13 The insurance industry is reluctant to offer liability insurance covering the costs incurred in repairing or replacing a defective building. Where available it is expensive and carries a high deductible. In New Zealand builders who fail to take care to avoid latent building defects are frequently uninsured and in effect avoid substantial liability costs. In practice the burden of compensating owners of defective buildings falls on territorial local authorities. Building controls in place in New Zealand are such that councils must take all reasonable steps to ensure compliance. See J Smillie "Compensation for latent building defects" [1990] NZLJ 310-34. Smillie proposes that owners be required to take first party insurance cover against building defects as a condition of a building permit.

14 Setting insurance premiums and compulsory levies according to categories of risk may go some way to offset the reduction in care, although if carried too far the insurance concept surely starts to fade. 
If the defendant is also disinclined or unable in law to seek contributions from other tortfeasors, such a defendant is known as a deep pocket, as for example international auditing firms (and their insurers), and territorial local authorities. The reasons why deep pockets may be disinclined or unable to join in other parties for contributions - management in the case of auditors or builders and suppliers of materials in the case of local authorities - are no doubt complex. For many reasons the private costs of suing for contributions are likely to be high. ${ }^{15}$

A deep pocket tends to become a sort of institutionalised insurance fund for plaintiffs and other tortfeasors. ${ }^{16}$ In the case of auditing firms, we must suppose that their fees reflect their role, while in the case of territorial local authorities society pays in the form of higher rates. The economic issue is again one of inefficiency and misallocation of resources produced by particular incentives.

The economic inefficiency that arises from the circumstances surrounding deep pockets and their response to incentives can be illustrated in the simple theory underlying Diagram 4 above. Compared with proportionate liability, solidary liability without contribution is inefficient. However, the possibility of contribution reduces the probability of loss (due to meeting damages) on the part of potential tortfeasors (ie auditors or territorial local authorities) and hence reduces their expected loss in dollars. Hence as Diagram 4 shows the optimal level of care is less than in the no contribution case, and with perfect confidence that all potential tortfeasors will pay their share the optimal level of care coincides with that in the proportionate case.

However, deep pockets by definition can not (do not?) rely on all potential tortfeasors paying up: consequently we must infer that the optimal level of care provided by auditors and territorial local authorities is greater than would be provided in the case of a solidary rule with contribution in the absence of deep pockets. It must be concluded that deep pockets result in economic inefficiencies associated with excessive levels of care and the consequent increases in cost to society. In the case of the building industry, local authorities insist on more regulations and controls than would otherwise be the case (and owners and builders exercise less care); in the case of auditing the result is less easy to pinpoint but probably

15 For overseas opinion see the first two references cited above $\mathrm{n} 3$.

16 In the economics literature there is no model of a deep pocket. However, a model of sorts has emerged during the course of the present inquiry: in the event of market failure, eg the absence of product liability insurance for defective buildings (referred to above), it could be argued that in certain industries a particular group of economic agents take advantage of the law and legal procedures to choose one agent - deep pocket - to provide de facto insurance. It follows that because the phenomenon of deep pockets is the result of a very complex situation, changing one feature of the situation may produce unexpected consequences. 
takes the form of a curtailment of financial services which auditors are otherwise peculiarly well placed to provide (and investors and managers exercise less care). ${ }^{17}$

The adoption of a proportionate liability rule (as proposed in the Australian Davis Report ${ }^{18}$ ), which would reduce the size of deep pockets' cost of negligence (assuming there are other negligent tortfeasors), whether some shares are uncollectible or not, almost certainly would have the effect of increasing the care undertaken by the plaintiff, whether homeowner or shareholder. The effect would be as if a form of cheap insurance for homeowners and shareholders were no longer available. In general this change would be economically beneficial, whatever the effect on deep pockets. And if, as suggested above, deep pockets under the present solidary liability regime have protected themselves by excessive levels of care, imposing an unnecessary burden of costs on the economy, the rule change may reduce this burden.

It is perhaps worth stressing that in reality the likelihood of uncollectible shares may not make a great deal of difference to the outcome of solidary liability, whether with or without contribution. The critical issue is probably whether the deep pocket is liable for all of the loss or only that part of the loss attributable to its negligence. A change of rule from solidary liability without contribution to solidary liability with contribution is likely to have little effect on auditing firms and territorial local authorities and on the prevailing economic inefficiencies.

\section{The Incidence of Costs}

At the beginning of this article we emphasised the economic or opportunity cost of care ie the alternative satisfactions forgone because (extra) resources were devoted to (extra) care. In this sense the cost of care is no different from the cost of producing any other good or service from scarce resources. Thus we can unambiguously say - at a high level of abstraction - that the cost of extra care is borne by all economic agents: all will be forced to tighten their belts slightly (more care taken in the New Zealand building industry makes the Chinese economy worse off!). It is these concepts which provide the criterion of the optimum allocation of resources (in short, economic efficiency) for use in economic analysis and policy choice.

However, like a tax - which at a high level of abstraction also falls on the entire economy - the cost of extra care affects different agents in different ways; and our related emphasis on the determinants of incentives for agents to choose optimum levels of care

17 One offsetting factor arises from the financial strength of the deep pockets: they can afford the expense of effective legal defences. We assume this is built into the probabilities and risks of the various parties.

Above $\mathrm{n} 2$. 
explicitly recognises that the cost of care can fall unevenly on different agents and on different sections of society. We have argued that the incidence of costs arising from a solidary liability rule without contribution would be sub-optimal. We have concluded that the consequences of the deep pocket phenomenon are likely to be sub-optimal, but could be moved towards optimality by the use of a rule of proportionate liability. We have pointed out that uncollectible shares by themselves do not reduce optimality, provided the possibility of uncollectible shares is recognised at the time of the agreement.

So far there has been no reference to equity or fairness, except in the subtly indirect sense that all of us gain from economic efficiency. This is not the place to develop a full scale analysis of equity, but it is important to indicate where considerations of equity enter the analysis and the conclusions.

We may suppose that the courts bring to bear supplementary tests one of which in certain circumstances concerns fairness. This requires the court to balance fairness with the level of care normally expected. It might be thought that such a situation has the effect of shifting the legally required degree of care back from, or beyond, that required by a simple application of the normal or customary rule. Fairness and efficiency are in conflict.

However, an alternative interpretation is to regard the supplementary test as referring to a particular social requirement, involving a particular social cost which must be added to the other costs surrounding the exchange in question (like a tax) and which inevitably alters the social optimum: fairness is a tradable good. From this point of view, the important issue about the introduction of supplementary tests like fairness is that they also must be generally accepted and understood, and that their application and reconciliation with the basic test of normal care must be predictable. If that is so, the incentives on which the economic efficiency argument is based remain intact.

The above discussion has led us back to the important idea that the relevant cost concept is expected costs (what economists sometimes call ex ante costs, distinguished from ex post or realised costs). This serves to emphasise the part played by expectations in the shaping of incentives, including the expectations of the ways that court proceedings will unfold in the event of disagreement.

\section{Conclusions}

What has economic analysis to say about the relative economic efficiency of the legal rules of liability?

1 Economic efficiency requires that all defendants exercise care at levels which minimise total expected cost which includes both the possible loss and the expense of providing care. A liability rule will provide incentives for potential injurers to choose particular levels of care. 
2 With several potential injurers and no likelihood of a missing defendant, proportionate liability (coupled with contributory negligence on the part of the plaintiff) provides the incentives for total cost minimisation, provided damages are correctly assessed and according to relative fault.

3 Solidary liability with no contribution increases the expected costs that each party would face when deciding the level of care to take. The additional costs arise out of the uncertainty over the allocation of damages between the joint tortfeasors. Solidary liability with no contribution is clearly less economically efficient than proportionate liability.

4 On the other hand, solidary liability with contribution reduces (or eliminates) this uncertainty and hence reduces the expected costs of the potential tortfeasors compared with the no contribution situation. Depending on the degree to which it reduces the uncertainty it is more economically efficient than the no contribution situation.

5 Subject to considerable qualification, proportionate liability is in theory neither more nor less economically efficient than solidary liability with contribution. However this conclusion assumes that the expectation of contribution eliminates all the uncertainty regarding the allocation of damages, that there are no deep pockets, and that the costs of litigation under solidary liability with contribution are similar to those under proportionate liability. In reality, for deep pockets at least, the costs of litigation almost certainly curtail the potential benefits from contribution and make solidary liability with contribution less efficient than proportionate liability.

6 The effect of the possibility of an absent co-defendant on the incentives for the remaining defendants depends upon the subsidiary rule used to allocate the absentee's share of the damages. Proportionate liability where the remaining defendants share the risk is economically efficient, and is similar, in terms of efficiency, to solidary liability with contribution (subject to the qualification noted in (5) above).

7 Deep pockets, such as accounting firms or territorial local authorities, by definition do not seek (or obtain) contributions from other tortfeasors, and can finance their exposure to damages claims either through insurance cover or ratepayers. Solidary liability applied to an industry with deep pockets does not produce the incentives which provide an efficient outcome. Deep pockets create an incentive for other potential tortfeasors to lower their standards because the likelihood of their facing damages claims is reduced. Plaintiffs are also likely to reduce their level of care.The response of the deep pockets (more building regulations and increased cost of audits or curtailed services) creates further inefficiencies.

8 For some deep pocket industries a change to a proportionate liability rule would undoubtedly alter the incentives to adopt economically efficient levels of care. On the 
other hand, the circumstances which produce the phenomenon of the deep pocket (other than the liability rule itself) may themselves be susceptible to change or reform, and may be an alternative to the adoption of a proportionate rule. Such possibilities have not been considered here, but we have in mind the procedures for joining in third parties which appear to increase uncertainty and make for high litigation costs.

9 Finally, proportionate liability contributes to economic efficiency because the potential injurer's liability for damage is measured by that injurer's level of responsibility or degree of fault, ie the extent to which the actual level of care departs from the economically optimal level. This legal rule, combined with insurance cover for negligent defendants and against the possibility of a missing or insolvent defendant, does provide the incentives for economic efficiency. In this respect proportionate liability would appear to provide a legal environment within which market mechanisms can operate with flexibility and efficiency. 